\title{
Contravisualidades: práticas de resistência em tempos de pandemia e fake news
}

\section{Carla Luzia de Abreu ${ }^{1}$}

Resumo: Este artigo objetiva contextualizar o agenciamento da subjetividade por meio da disseminação de fake news e como essa mesma manipulação de fatos desencadeia outros processos de subjetivação, sustentados por contracondutas e a produçã̃o de contravisualidades. As reflexões apoiam-se em referenciais do campo da cultura visual e da filosofia e, por fim, apresenta exemplos de contravisualidades que promovem deslocamentos nas formas de 'ver' o mundo.

Palavras-chave: cultura visual, controle, fake news, contravisualidades

\section{Countervisualities: resistance practices in times of pandemic and fake news}

Abstract: This article aims to contextualize the agency of subjectivity through the dissemination of fake news and how this same manipulation of facts triggers other processes of subjectivation, supported by counter-conduct and the production of countervisualities. The reflections are based on references in the field of visual culture and philosophy and, finally, presents examples of countervisualities that promote displacements in the ways of 'seeing' the world.

Keywords: visual culture; control; fake news; countervisualities

1 Docente na Faculdade de Artes Visuais, Universidade Federal de Goiás (FAV-UFG), onde também atua no Programa de Pós-Graduação em Arte e Cultura Visual (PPGACV-UFG). Doutora em Artes Visuales y Educación (Universitat de Barcelona, Espanha). Atualmente faz estágio pós-doutoral no Programa de Pós-Graduação em Educação, na Universidade Estadual do Rio de Janeiro. Universidade Federal de Goiás (FAV-UFG). E-mail: carlaabreu@ufg.br. ORCID: https://orcid.org/0000-0002-7320-1845. Lattes iD: http://lattes.cnpq.br/1430560976125427. Goiânia, Brasil 


\section{Introdução}

Neste texto discuto o agenciamento da subjetividade por meio da manipulação e a difusão de fake news, uma característica importante do mundo contemporâneo, e como essa mesma manipulação desencadeia outros processos de subjetivação sustentados por contracondutas e a produção de contravisualidades que confrontam o estado naturalizado das narrativas hegemônicas. As reflexões apoiam-se em referenciais teóricos do campo da cultura visual e da filosofia e buscam pensar as atividades de resistência que confrontam os discursos oficiais.

O mundo está ruidoso. Não há calma e nem alento na contemporaneidade. Desde o início do século 21 vivemos sequências de circunstâncias dramáticas: a crise climática; guerras contra o terrorismo; aumento da xenofobia em resposta aos processos imigratórios; uma progressiva restrição das liberdades civis e uma crescente ascensão da ultradireita no mundo, mostrando uma face sombria daqueles que estão à frente das decisões políticas e de parte da população que os elege para ocupar os cargos públicos.

No Brasil, entre 2017 e 2020, vivenciamos um golpe de Estado que eclodiu no impeachment da presidenta democraticamente eleita, Dilma Rousseff. Houve a extinção do Ministério da Cultura e do Trabalho e o assassinato de Marielle Franco e de seu motorista, Anderson Gomes, por motivos ainda não esclarecidos. Vimos um incêndio de grande proporção destruir o Museu Nacional; houve execuções de líderes ambientais e indígenas; e, vimos as cenas dantescas do rompimento da barragem em Brumadinho. As florestas pegaram fogo, intencionalmente provocados; assistimos as imagens de nossas praias do litoral nordestino serem cobertas por um óleo pegajoso e misterioso. E, assombrados, vemos cenas de pessoas que ocupam o espaço público para pedir o retorno da ditadura militar.

Muitos de nós sofremos na pele a censura a exposições e projetos artísticos e, tristemente, presenciamos o desmonte da Educação Pública no Brasil, dilapidada por cortes orçamentários e a extinção de bolsas de pesquisa. No atual momento político, a educação e os(as) trabalhadores(as) da área são considerados(as) inimigos(as) importantes, sendo combatidos em várias frentes. A educação como alvo prioritário de ataques das sanções políticas não é aleatória. Os dispositivos de poder sabem que as escolas e as universidades públicas são espaços de resistência e de promoção do pensamento crítico.

Todas essas notícias são acompanhadas de uma abundante propagação de fake news, difundidas nas redes sociais e nos aplicativos de comunicação. As 
notícias falsas foram inclusive as principais responsáveis pelo resultado do processo eleitoral no Brasil, em 2018, que levou à presidência do país, Jair Messias Bolsonaro. Inclusive, uma Comissão Parlamentar Mista de Inquérito (CPMI) foi montada no Congresso Nacional para investigar ataques cibernéticos e o uso de perfis falsos para influenciar o resultado das eleições ${ }^{1}$.

Entre março e abril de 2020, momento em que escrevo este artigo, parte da população encontra-se cumprindo as recomendações de isolamento social da Organização Mundial de Saúde, como estratégia para combater a Covid-19, um vírus tratado como pandemia que já deixou um rastro de milhares de mortes em todo o mundo. A sensação é de pesar pelas pessoas que sucumbiram ao vírus e de incerteza em relação ao futuro, especialmente em como se configurará a vida cotidiana após a pandemia. A previsão é uma recessão econômica sem precedentes a nível mundial.

Com o olhar voltado aos interesses econômicos, Jair Bolsonaro, mesmo com as estatísticas dos efeitos da Covid-19 e indo em direção contrária aos dirigentes de outros países, incentiva a população a sair do isolamento social e voltar a ter uma vida normal, falas que são amplamente divulgadas em suas redes sociais. A morte, segundo o mesmo, é abordada como algo natural, algo que acontecerá a todos, mas, a economia, não pode parar: "Infelizmente algumas mortes terão. Paciência, acontece!", disse Bolsonaro².

Neste momento, esta postura do presidente é um convite à morte. $\mathrm{O}$ comportamento de Bolsonaro, apesar de se autodenominar uma pessoa religiosa, desafia o quinto mandamento: "Não matarás"! A proibição moral de matar, no entanto, não anula a intenção de matar. Ao jogar à própria sorte a população mais vulnerável, fica evidente que o Estado assume a política da morte seletiva. Essa prática foi descrita pelo filósofo camaronês Achille Mbembe como necropolítica: "normas contemporâneas que subjugam a vida ao poder da morte (necropolítica) reconfiguram profundamente as relações entre resistência, sacrifício e terror" (2016, p. 146).

1 Conhecido como CPMI da Fake News, o texto do requerimento, ainda em trâmite, diz que são analisadas práticas que "atentam contra a democracia e o debate público", além de considerarem a "presença de perfis automatizados, ou robôs, que representam um risco à lisura do debate público e do processo eleitoral". Fonte: Senado Notícias. 04.09.2019. <https://www12.senado.leg.br/noticias/materias/2019/09/04/cpmi-das-fake-news-e-instalada-no-congresso>. Consultado em 19.02.2020.

2 Bolsonaro em entrevista ao apresentador José Luiz Datena, programa Brasil Urgente da TV Band. Fonte: < https://youtu.be/Q8DaRmkkkq8>. Consultado em 28.03.2020. 
Necropolítica, então, é o poder de decisão sobre quem morre, onde morre e como morre. O termo vem sendo bastante usado para explicar o que acontece no Brasil e entender como o Estado se torna mortal para a população vulnerável. Em tempos de pandemia e ao relativizar a gravidade da situação, Bolsonaro compromete a saúde de milhões de brasileiros(as) que não podem se defender do coronavírus ou cumprir a recomendação de isolamento social, seja pela ausência de saneamento básico, dificuldade de acesso ao sistema de saúde público, falta de recursos materiais de higienização, porque os empregadores não liberaram seus empregados ou pelo número considerável de trabalhadores informais que necessitam sair às ruas diariamente para sobreviver.

O discurso político pressiona a sociedade para voltar à 'normalidade', mesmo que uma parcela significativa da população precise morrer. É a lógica assumida pelas necropolíticas que opera com a ideia de que alguns valem mais que outros. Ao priorizar a economia do país em detrimento de vidas humanas, o Governo busca extrair dividendos para atender aos interesses do mercado financeiro. $O$ mais assustador é que apesar de muitos fatos sucessivos de mentiras, agressões e ataques direcionados a grupos específicos e instituições públicas, Bolsonaro continua a manter uma rede razoável de apoiadores na sociedade civil.

O filósofo Byung-Chul Han (2018) argumenta que o neoliberalismo marca uma "mutação do capitalismo" e, nessa nova fase, a força produtiva se dá pelo controle da psique, elemento fundamental de monitoramento das condutas, dos comportamentos, desejos e das escolhas dos indivíduos. A partir de uma perspectiva foucaultiana, o filósofo aponta que o psicopoder age não apenas no disciplinamento dos corpos, mas também em estados psíquicos e subjetivos dos indivíduos. Segundo o filósofo, esse período caracteriza um giro da biopolítica para a psicopolítica. Em suas palavras:

A virada para a psique e, em consequência, para a psicopolítica, também está relacionada à forma de produção do capitalismo atual, pois ele é determinado por modos imateriais e incorpóreos. São produzidos objetos intangíveis, como informações e programas. O corpo como força produtiva não é mais tão central como na sociedade disciplinar biopolítica. Em vez de superar resistências corporais, processos psíquicos e mentais são otimizados para o aumento da produtividade. O disciplinamento corporal dá lugar à otimização mental. (2018, p. 40)

A psicopolítica só foi possível graças à sociedade digital. O psicopoder não está interessado em silêncios ou proibições disciplinares, ao contrário, "ele nos convida a compartilhar incessantemente, participando, dando opiniões, comunicando necessidades, desejos e preferências, contando sobre nossa 
própria vida" (HAN, 2018, p. 27). Segundo Han, no neoliberalismo "o smartphone não é apenas um aparelho de monitoramento eficaz, mas também um confessionário móvel" (p. 24). Trata-se de uma nova modalidade da sociedade de controle, em que a comunicação e o sujeito digitalizado são as peças que fazem a roda gerar, na qual a vigilância é delegada a todos os indivíduos: "Cada um é o panóptico de si mesmo" (p. 58).

Nesses termos, o Brasil está em segundo lugar no ranking de países que mais passam tempo em redes sociais, segundo a pesquisa da GlobalWeblndex $^{3}$. De fato, a psicopolítica depende desse comportamento para existir, sobrevive do fluxo continuo e do consumo não reflexivo das informações que circulam nos meios digitais. Esse é o principal mecanismo de controle da psique. O neoliberalismo precisa que os sujeitos continuem a usar freneticamente as redes sociais, produzir e consumir dados, para manter a produção de subjetividades que projetam a realidade do mundo e promovem os padrões coletivos de comportamento.

Tal posicionamento reitera a ideia de Foucault (2008) de que o Estado está mais preocupado com o poder do que com a repressão. Interessa o controle da conduta dos indivíduos. A isso, o filósofo deu o nome de governamentalidade, um neologismo que funde as palavras Governo e Mentalidade. Em tempos atuais, o neoliberalismo usa a governamentalidade para criar categorias de sujeitos, inserindo e excluindo aqueles que não se encaixam na nova forma de 'consumir' o mundo.

A governamentalidade se dá pela valorização das condutas obedientes ao poder, mas, por outro lado, também desperta reações, insurgências e contracondutas. Para Rago e Pelegrini (2019), as contracondutas "são possibilidades de construir inventivamente novas formas de se colocar no mundo, novas oportunidades de constituição da subjetividade, novas ideias para relacionar-se consigo e com os outros" (pp. 10-11). Do mesmo modo, para Foucault (2008), as contracondutas consistem em

movimentos que têm como objetivo outra conduta, isto é: querer ser conduzido de outro modo, por outros condutores e por outros pastores, para outros objetivos e para outras formas de salvação, por meio de outros procedimentos e de outros méto-

3 A empresa analisou dados de 45 dos maiores mercados de internet do mundo para detectar as principais tendências de usuários na internet. Fonte: Relatório GlobalWeblndex, 2019: <https://www.globalwebindex.com/reports/social>. Consultado em 10.02.2020. 
dos. São movimentos que também procuram, eventualmente em todo caso, escapar da conduta dos outros, que procuram definir para cada um a forma de se conduzir. (2008, p. 256-257)

Em tempos de pandemia, insegurança e desesperança, a internet se tornou um território amplo de demonstrações de condutas submissas ao poder, mas, também, de contracondutas reativas, práticas de resistência e liberdade que buscam caminhos para a criação de novos processos de subjetivação, valorização da vida e das diferenças. São contrarreações ao neoliberalismo, seus robôs informáticos e seu poder econômico que sustenta uma malha invisível, porém bastante materializada, de mentiras e violações nos canais digitais. As práticas de resistência divulgadas e difundidas nas redes sociais expressam a necessidade de se opor ao controle imposto pelas psicopolíticas e as necropolíticas, e resistir a elas.

\section{A mentira disfarçada de verdade}

A estratégia de enganar, iludir, espalhar boatos ou disseminar rumores é muito antiga e um dilema filosófico e artístico secular. O que mudou na contemporaneidade foi a amplitude de seu alcance e a dificuldade de se acurar a veracidade da informação, facilitando situações em que, muitas vezes, a mentira parece travestida de verdade. Existe uma parábola antiga que descreve o encontro entre a Verdade e a Mentira. Há várias versões desse conto, apresento a mais conhecida:

Um dia, a Verdade e a Mentira se cruzaram e se cumprimentaram. A Mentira diz à Verdade: 'está muito bonito hoje'. A Verdade olha à volta, olha o céu, o dia está realmente bonito. A Verdade vê que nisso a Mentira não mentiu. Seguiram juntas até chegarem a um poço onde a Mentira diz à Verdade: 'A água está muito agradável, vamos tomar banho juntas?' A Verdade mais uma vez desconfiada põe a pontinha do pé na água, é, realmente está agradável e refrescante. Decide tirar suas roupas, entrar no poço e nadar onde a Mentira mais do que depressa já se havia despido e se jogado fazendo grande alarde de como a água estava maravilhosa. De repente, a Mentira sai da água, se veste com as roupas da Verdade e foge. A Verdade fica furiosa sai do poço procurando por todos os lados encontrar a Mentira e recuperar suas roupas. Mas a essa altura, a Mentira já andava longe. O mundo vendo a Verdade nua vira o olhar com desprezo e raiva. A pobre Verdade volta para o poço e desaparece para sempre escondendo a sua vergonha. Desde então, a Mentira viaja pelo mundo vestida como a Verdade, satisfazendo todos que não querem em nenhuma hipótese aceitar a Verdade, muito menos, nua. ${ }^{4}$

4 Fonte: < https://www.hette.com.br/cc/verdment.htm>. Consultado em 10.02.2020. 
Figura 1 Jean-Léon Gérôme, La Vérité sortant du puits armée de son martinet pour châtier l'humanité (1896). Fonte: $<$ https://musees. allier.fr/417-archives.htm>

Figura 2 Gustav Klimt, Nuda Veritas (1889). Fonte: <https://www. gustav-klimt. com/Nuda-Veritas.jsp>
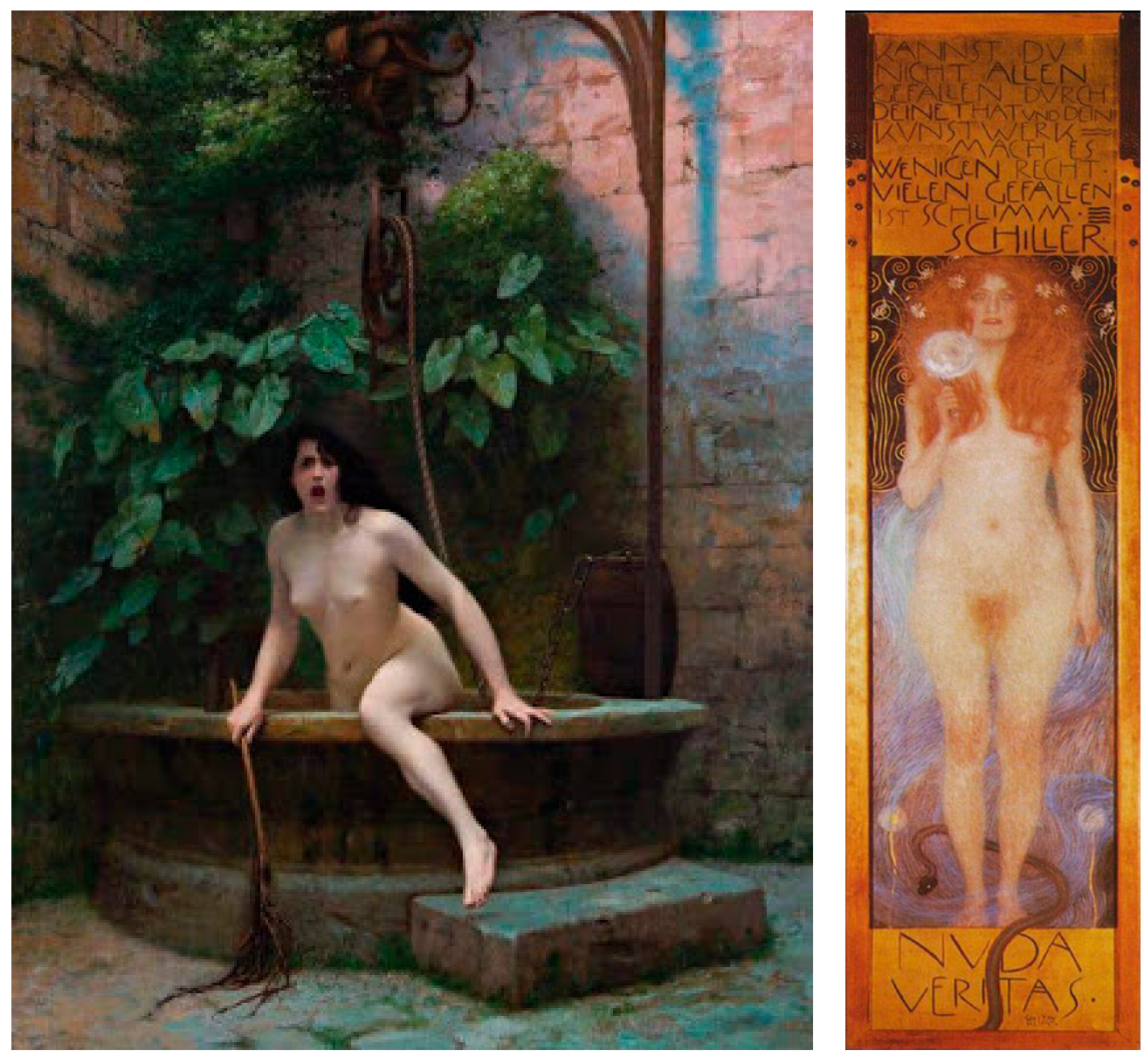

Segundo a parábola, desde então preferimos aceitar a mentira disfarçada de verdade do que a verdade 'nua'. Essa temática inspirou alguns artistas, entre eles, Jean-Léon Gérôme ${ }^{5}$ e Gustav-Klimt ${ }^{6}$ que produziram as obras $A$ verdade saindo do poço (1896) e Nuda Veritas (1889), respectivamente. O quadro de Jean-Léon Gérôme faz referência às palavras do filósofo grego Demócrito (460 - 370 a.C.): "Da verdade não sabemos nada, porque a verdade está em um poço". Já na pintura de Gustav-Klimt, na parte superior da tela, há uma frase do poeta alemão Friedrich Schiller: "Se você não puder agradar a todos com suas ações e sua arte, agrade a alguns. Agradar

5 Jean-Léon Gérôme (1824 - 1904), pintor e escultor francês, considerado academicista.

6 Gustav Klimt (1862 - 1918), pintor e desenhista austríaco, simbolista e um dos grandes nomes da art nouveau. 
a muitos é ruim"7. Ambos pintores representam a Verdade desnuda. Gérôme acrescenta um chicote em suas mãos e a expressão de fúria no rosto da Verdade enganada pela Mentira. Klimt representa a Verdade com um espelho nas mãos; o espelho está voltado para quem vê a imagem frontalmente, como um convite a olhar para si mesmo.

No século 21, com o desenvolvimento tecnológico, boatos e mentiras são disseminadas com muita rapidez, através de uma rede gigantesca de atores interconectados na internet. Além disso, as ferramentas digitais também facilitaram a manipulação das informações, de imagens e vídeos, borrando ainda mais as fronteiras entre o real e aquilo que foi manuseado para transparecer como "verdade". Nessa nova dinâmica da vida, a checagem das informações não ocorre na mesma velocidade e frequência necessária para conter o compartilhamento e a pulverização de desinformações, mentiras ou meias-verdades.

A produção de subjetividades coletivas por meio das ferramentas digitais configura a dinâmica de um sistema complexo de dados e de visualidades que dão origem a comportamentos coletivos e depende das ações individuais dos sujeitos conectados, não estando sob o controle de um comando central. Daí a imprevisibilidade dos efeitos quando são 'viralizadas' informações falsas e boatos.

O cenário ficou ainda mais turbulento com a entrada dos algoritmos informáticos intencionalmente criados para o controle da 'psique' dos sujeitos. São programas desenvolvidos para potencializar ainda mais o alcance das narrativas ficcionais e promover padrões coletivos de comportamento. É o que vem sendo chamado de Big Data - tecnologia desenvolvida para rastrear e coletar nossas ações na internet - opera para definir estratos de consumidores e a propagação de notícias falsas. E, nós, gentilmente lhes oferecemos o registro total de nossas práticas, gostos, afetos e desafetos.

Os robôs (bots) agem na internet não apenas espalhando fake news e promovendo a instabilidade psicossocial, mas também são fontes de validação das informações, porque "simulam sua legitimidade com infinitos likes instantaneamente produzidos por tais robôs, o que as faz parecer massivamente aceitas, intensificando e propagando sua ilusória credibilidade" (ROLNIK, 2018, p. 161).

7 Tradução livre de: "Kannst du nicht allen durch deine That und dein Kunstwerk, mach es wenigen recht. Vielen gefallen ist schlimm". 
A professora Suely Rolnik (2018) aponta a necessidade de "resistir no próprio campo da política de produção da subjetividade" (p. 36). Para a autora, é preciso criar novos modelos de existência que transcendem a cognição das subjetividades coletivas e das condutas normatizadas. Isso implicaria abandonar a aceitação inconsciente das dinâmicas das psicopolíticas para que outras subjetividades possam tomar seu lugar, de acordo com o contexto sociopolítico e cultural de cada grupo social.

Os produtos da cultura visual no mundo contemporâneo - como imagens ou vídeos -realizam um papel fundamental na dinâmica das psicopolíticas, uma vez que potencializam a circulação das informações. Os artefatos visuais estabelecem pontes com nossas formas de pensar e experimentar o mundo e têm exercido um papel fundamental na produção de formas de controle da psique, como advertiu Byung-Chul Han (2018).

O problema, no caso da ampla produção e consumo de dados que circulam na internet, é que nem sempre é acompanhada de reflexão sobre sua autenticidade ou relevância, produzindo interpretações esvaziadas ou equivocadas. Várias notícias veiculadas nas mídias sociais e, muitas vezes, nos próprios canais de comunicação hegemônicos, são criadas para espalhar pânico, calúnias e distorções de fatos, cumprindo a função das psicopolíticas de produzir determinados comportamentos sociais.

Uma observação atenta das informações que circulam pelos meios digitais aponta que os interesses políticos e econômicos demarcam o território das narrativas dominantes, propagando os velhos e sempre renovados preconceitos e toda sorte de discriminação. O resultado são interpretações que vão além da representação visual ou da linguagem.

Para W. J. T. Mitchell (2015), a visão é tão importante quanto a linguagem na mediação das relações sociais. Para ele, o ato de ver e interpretar o que se vê, não está restrito à linguagem, ao signo ou ao discurso: "O problema é refinar e complexificar nossa estimativa acerca desse poder [das imagens] e do modo como ele se exerce" (p. 171).

Os estudos da Cultura Visual entendem que as imagens são artefatos culturais que conformam regimes de visualidades que, por sua vez, são configurados por meio de elementos políticos, epistemológicos e de valores morais, estéticos e éticos. Mirzoeff (2016) explica que cultura visual é tanto o nome de um campo acadêmico quanto o de seu objeto de estudo: 
A cultura visual inclui as coisas que vemos, o modelo mental de visão que todos temos e o que podemos fazer como consequência disso. (...) Uma cultura visual não é simplesmente a soma de tudo que foi feito para ser visto, como imagens ou filmes. Uma cultura visual é a relação entre o visível e os nomes que damos ao visto. Também abrange o invisível ou o que está oculto. (pp. 19-20)8.

Portanto, toda cultura supõe uma construção visual do social, além de uma construção social do visual (MITCHELL, 2002, p. 175). Nesse sentido, examinar as marcas e influências das visualidades implica analisar as formas como aprendemos a ver e como essas formas estão impregnadas de discursos de agenciamentos diversos que adestram o olhar.

As pesquisadoras Elisenda Ardèvol e Nora Muntañola (2004) explicam que a interpretação das imagens depende de convenções aleatórias mediante as quais aprendemos a traduzir seus significados a partir de comportamentos culturais. Desse modo, as imagens acabam sendo um elemento que participa ativamente na configuração dos universos simbólicos e, nesse sentido, também fazem parte da formação das subjetividades coletivas.

Em sua genealogia histórica sobre as imagens, Nicholas Mirzoeff (2016) se refere à noção de visualidade como um conjunto de mecanismos que tem o poder de organizar e dar forma às estruturas de poder: "este processo não é composto apenas de percepções visuais no sentido físico, mas é formado por um conjunto de relações que combinam informação, imaginação e introspecção em uma interpretação do espaço físico e psíquico" (p. 748). Os complexos de visualidade, como definiu o autor, trabalham para legitimar a hegemonia ocidental, naturalizando o poder através da classificação, da separação e da estetização dos artefatos culturais.

Como mencionado, as psicopolíticas incentivam o consumo alienado e irracional das tecnologias. No Brasil, o complexo de visualidades, por intermédio de um amplo leque de imagens estáticas ou em movimento, alimenta os discursos racistas e homo-trans-fóbicos, ajuda a minimizar ou ridicularizar a violência de gênero ou crimes de estupro, colabora na dis-

8 Tradução livre de: "La cultura visual incluye las cosas que vemos, el modelo mental de visión que todos tenemos y lo que podemos hacer en consecuencia. (...) Una cultura visual no es simplemente el soma de todo lo que ha sido hecho para ser visto, como los cuadros o las películas. Una cultura visual es la relación entre lo visible y los nombres que damos a lo visto. También abarca lo invisible o lo que se oculta a la vista." (MIRZOEFF, 2016, pp. 19-20) 
torção de fatos incômodos ao poder, fortalece uma estética militarizada entre a sociedade civil e contribui na exaltação de sujeitos que deveriam ser questionados e não homenageados.

O governo de Jair Bolsonaro faz uso eficiente das ferramentas digitais e conta com um exército de robôs a seu serviço, cujo financiamento de tais atividades a CPMI da Fake News trata de investigar. Usa esses mecanismos para atacar, criticar a imprensa, distorcer fatos e espalhar notícias que rotineiramente são desveladas como falsas, conforme já apurado pelas principais mídias brasileiras. As tecnologias digitais são armas políticas neste governo e, as redes sociais, produtos discursivos e canais de propaganda institucional.

Um estudo divulgado no início de Abril de $2020^{9}$, realizado pela Universidade Federal do Rio de Janeiro (UFRJ) e pela Fundação Escola de Sociologia e Política de São Paulo (FespSP), coordenado pelas professoras pesquisadoras Rose Marie Santini, da UFRJ, e Isabela Kalil, da Fesp, indicou que $55 \%$ de publicações pró-Bolsonaro são feitas por robôs, ou seja, contas automatizadas ou semiautomatizadas replicadoras. 0 estudo analisou 1,2 milhão de posts no Twitter, entre 1 de janeiro e 15 de março. A estratégia, segundo as pesquisadoras, demonstra evidências de uma ação coordenada e planejada, práticas claramente usadas para manipular a opinião pública.

Na pandemia da Covid-19, Bolsonaro se esforça para criar um clima de instabilidade política, minimizar os efeitos do vírus e propagar um estado de insegurança na sociedade, como foi o caso da postagem em sua conta no Twitter, no dia 25 de março de 2020, quando defendeu a hidroxicloroquina como remédio eficaz para o tratamento de pessoas infectadas pelo coronavírus ${ }^{10}$. Essa notícia foi replicada centenas de vezes pelos robôs responsáveis pela máquina de likes, visualizações e compartilhamentos. A propagação massiva dessas informações resulta em interpretações equivocadas cujas contaminações interferem nas formas como construímos sentido àquilo que nos chega.

9 O Globo, 03.04.2020. Fonte: <https://oglobo.globo.com/brasil/mais-da-metade-dos-tuites-favoraveis-bolsonaro-sobre-os-atos-do-dia-15-o-coronavirus-foram-feitos-por-robos-24349628>

10 Folha de São Paulo, em 01.04.2020. Fonte: <https://www1.folha.uol.com.br/ poder/2020/04/no-dia-da-mentira-veja-frases-ditas-por-bolsonaro-desde-a-posse.shtml?fbclid=IwAR3CWL6npbDK7HfmKa-3hZmTmjtbih4wXdfigNz0gQO8kU6dHd_Yoj6tSac> 
Bolsonaro, como chefe de Estado, sabe dos efeitos que suas publicações causam na população. No caso da crise provocada pela Covid-19, o comportamento do presidente, apesar de não matar diretamente, leva a mensagem que o vírus é banal e incentiva milhares de pessoas a adotar atitudes perigosas que colocam suas vidas em risco. Afinal, "o bot não vota nem adoece de covid-19, por exemplo, mas influencia a forma como os humanos votam e se previnem ou não diante de uma pandemia", explica a pesquisadora Isabela Kalil, doutora em Antropologia Social e uma das autoras do estudo citado anteriormente.

Um efeito colateral das medidas adotadas pelo Governo desde o início da pandemia foi o reaparecimento do sentimento de indignação social e o reconhecimento da importância da ciência, da saúde pública e da educação como elementos essenciais para a sobrevivência desse planeta. Nessa direção, se por um lado os regimes de verdade operam na propagação e fortalecimento dos discursos de poder, por outro, também despertam em algumas pessoas o direito à legítima defesa, o direito de conhecer a verdade e de proteger a vida, fazendo surgir novas formas de lutas e resistências. Essa desobediência abre caminho para a criação de novas subjetividades que podem resultar em uma 'desidentificação' com as significações que são produzidas pelas psicopolíticas e seus efeitos na psique dos indivíduos.

\section{Contravisualidades: criação de outras narrativas e disseminação de afe- tos e solidariedade}

As tecnologias digitais colaboraram para a invenção de novas contracondutas que rompem com a hegemonia das narrativas dominantes. Dentro desse espírito de insurgências, Nicholas Mirzoeff (2011), no livro The Right to Look, apresenta o conceito de contravisualidade como um caminho alternativo para a construção de novas significações. $O$ autor rompe com a noção de visualidade como sendo uma simples percepção e define o conceito como a articulação entre informação, imaginação e uma compreensão que se dá de forma subjetiva sobre o que se vê.

Para o autor, visualidade é uma prática discursiva de manipulação e regulação da realidade que produz efeitos reais, ou seja, visualidade é entendida como uma matriz de poder. $\mathrm{O}$ autor se refere às estruturas que agem persuasivamente na organização social, separando e categorizando os sujeitos, sob o véu do moralmente e politicamente defensável. 
A regularidade e homogeneidade das visualidades não se instala sem conflitos. Os discursos que delas derivam são frequentemente questionados pela pluralidade das experiências coletivas e individuais que constroem narrativas visuais não oficializadas, como estratégia para contrapor as formas como representamos e somos representados. Essas contranarrativas têm a potencialidade de romper com as diretrizes dominantes e provocar deslocamentos em torno das compreensões elaboradas a partir dos discursos hegemônicos: “O 'realismo' da contravisualidade é o meio pelo qual alguém tenta dar sentido à irrealidade criada pela autoridade da visualidade, ao mesmo tempo em que propõe uma alternativa real." ${ }^{11}$ (MIRZOEFF, 2011, p. 485)

Para resistir e fazer frente aos efeitos dos complexos de visualidade, Mirzoeff reivindica o "direito de olhar" e não apenas "ver a realidade" construída pelo regime de visualidade hegemônica. As contravisualidades ajudam a questionar o círculo da homogeneização do olhar, em que os dispositivos visuais formalizam o que é representável e o que não pode ser visto. As contravisualidades, portanto, são alternativas para narrar outras realidades, em que a presença do 'outro' invisibilizado é requisitada.

A potencialidade das contravisualidades está na ação de promover outras narrativas e incentivar deslocamentos nas formas como aprendemos a 'ver' o mundo. Mirzoeff (2011) propõe compreender as contravisualidades como manifestações políticas que desafiam determinadas "ordens" e delimitações das estruturas de poder, provocando ruídos e tensões. As contravisualidades, portanto, oferecem ferramentas que ajudam a desnaturalizar o olhar homogeneizado produzido pelo complexo de visualidade.

Contestar as visualidades dominantes nem sempre resulta ser um processo fácil, principalmente em contextos políticos conservadores e em tempos de fake news. Mas, é no mínimo necessário se buscamos aprender com e por meio das imagens. É sempre bom lembrar que as produções artísticas e as imagens formam parte do lento processo de transformação cultural e participam dos movimentos de resistência e questionamento sobre aquilo que afeta diretamente as práticas de subjetividade das pessoas.

11 Tradução livre: "The "realism" of countervisuality is the means by which one tries to make sense of the unreality created by visuality's authority while at the same time proposing a real alternative"3. (MIRZOEFF, 2011, p. 485) 
Para ilustrar um exemplo de contravisualidades, mencionamos os coletivos artivistas que têm desenvolvido atividades de projeções nos edifícios das grandes cidades, alterando o cotidiano da paisagem urbana. Desde o final de 2019 , as pessoas que transitam pelo movimentado centro da cidade de São Paulo têm visto projeções em prédios da rua Consolação. Em geral, são frases críticas e provocações sobre o contexto político. As projeções foram organizadas pelo coletivo "Projeção Consolação"12, formado por pessoas com formação em áreas distintas: ciência política, relações internacionais, tecnologia da informação e artes. O Grupo não pede autorização para realizar as projeções e diz que também nunca sofreu sanções do poder público, classificando suas ações como "protestos pacíficos", algo que é garantido pela Constituição Brasileira ${ }^{13}$.

Com o passar dos meses e com o agravamento das tensões políticas provocadas pela crise da Covid-19, a ideia das projeções nos edifícios se alastrou e outros coletivos foram formados. Cidades como Belo Horizonte, Brasília, Salvador, Recife e Rio de Janeiro já foram palco para as projeções ativistas. O coletivo Projetemos ${ }^{14}$ é provavelmente o maior e já conta com mais de 150 pessoas envolvidas no projeto. O Grupo se mobiliza para elaborar ações coordenadas de conscientização e informação contra a pandemia do coronavírus e também, no caso do Brasil, denúncias contra o Governo.

"Vai dar Tudo Certo", "Ligue Para a Sua Avó", "Fiquem Em Casa”, "Ficar Em Casa É o Remédio Mais Barato Contra o Corona Vírus" e "Todo Mundo Deveria Ter o Direito de Ficar em Quarentena" são algumas das muitas frases projetadas nos edifícios. O coletivo Projetemos também está composto por profissionais multidisciplinares, de várias partes do mundo (Europa, Ásia e América do Sul), tais como: VJs (vídeo jockeys), vídeo makers, designers, jornalistas e poetas.

Visando ampliar e democratizar suas ações, o Projetemos criou um website $\mathrm{e}^{15}$ que funciona como um aplicativo de textos editáveis em que qualquer

12 O Coletivo publica imagens das projeções em seu perfil no Instagram: @projecaoconsolacao

13 Piauí, edição 162, março de 2020. Fonte: <https://piaui.folha.uol.com.br/materia/ luzes-na-cidade-projecao-consolacao/>

14 O Coletivo publica imagens das projeções em seu perfil no Instagram: @projetemos

15 www.projetemos.com.br 
pessoa pode criar sua própria frase e programar (mapear) o espaço da projeção. Agora, "é só apontar o projetor pra parede e escrever. Estamos deixando o poder onde é o lugar dele, com o povo", diz o VJ Mozart Santos, cocriador do Coletivo, conforme esclarece no texto de divulgação do grupo, gentilmente enviado por e-mail para a publicação deste artigo.
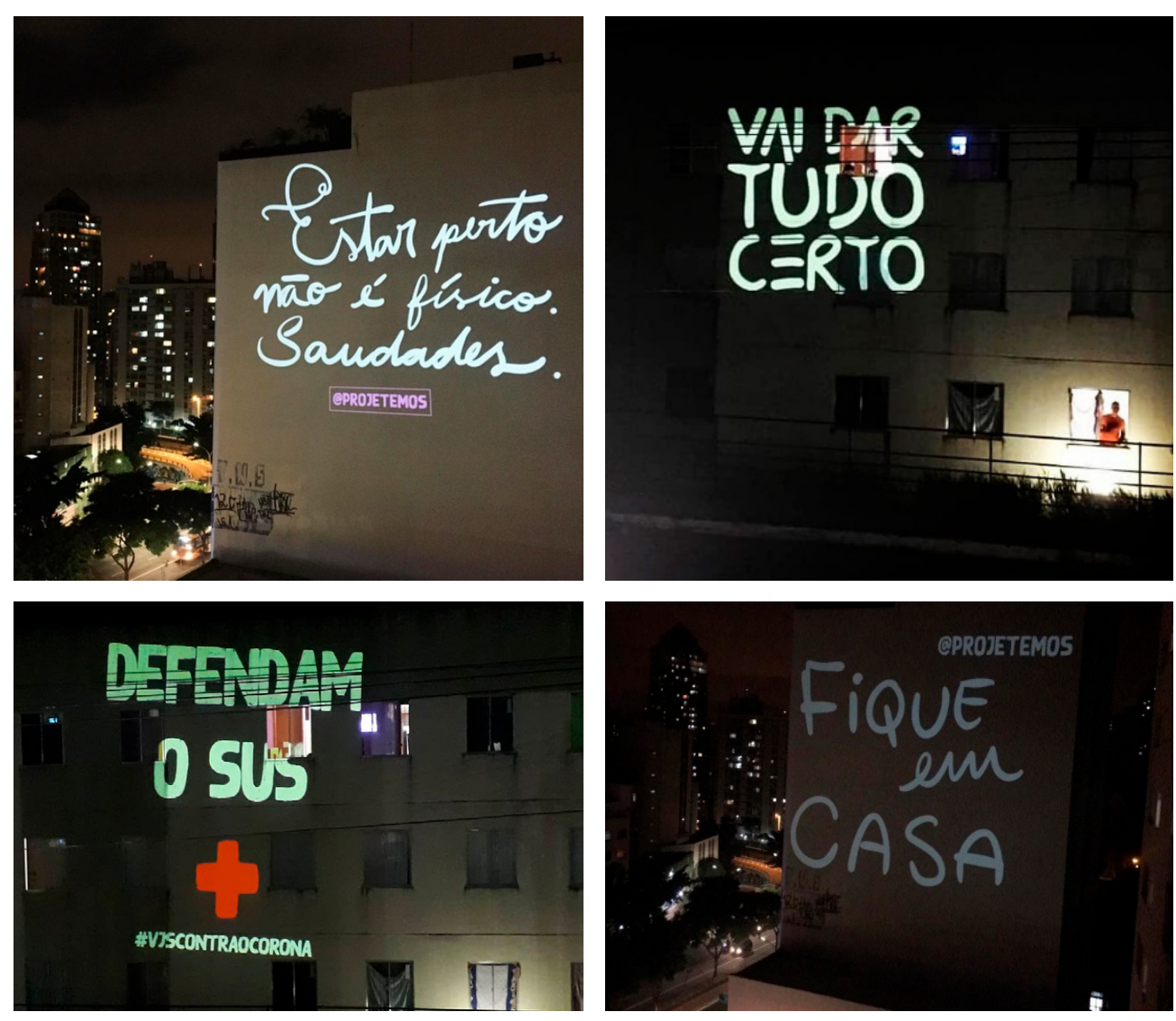

Figura 3.

Fotos de projeções realizadas pelo Coletivo

Projetemos, gentilmente cedidas para constarem neste artigo.
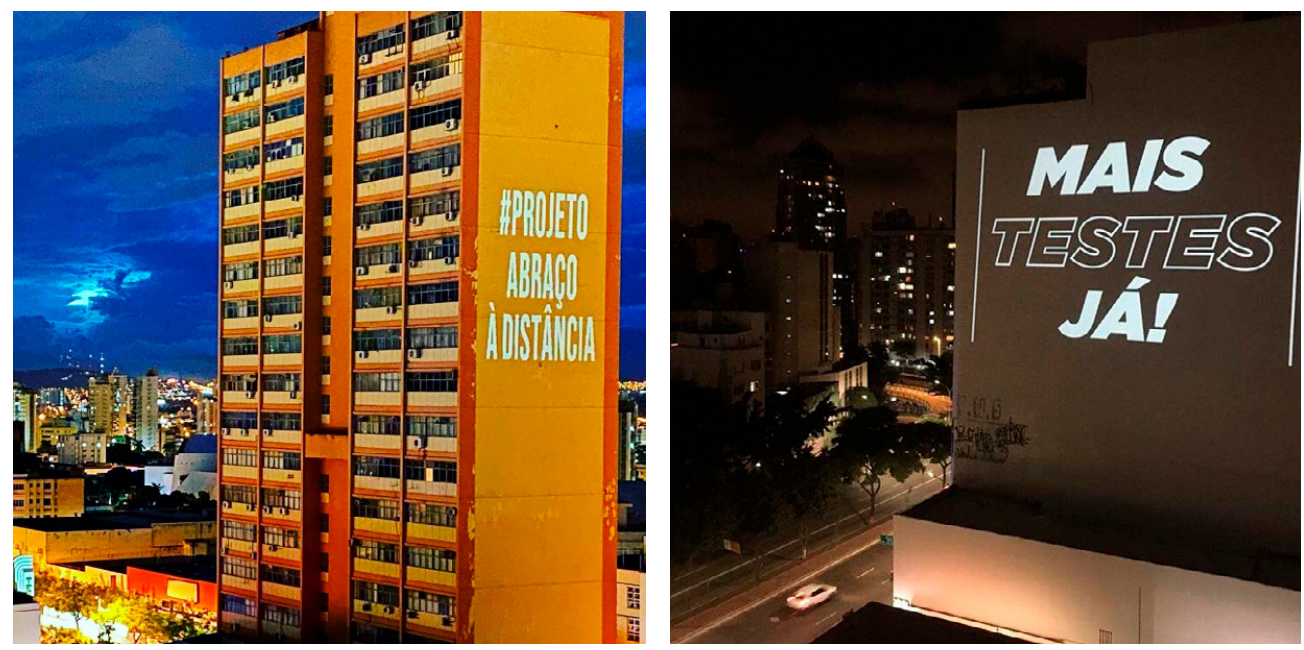
Aprendemos com Michel de Certeau (2019, p. 184) que 'lugar' "é a ordem (seja qual for) segundo a qual se distribuem elementos nas relações de coexistência", portanto estável e normativo. Por outro lado, 'espaço' "é um cruzamento de móveis. É de certo modo animado pelo conjunto dos movimentos que aí se desdobram. (...) Em suma, o espaço é um lugar praticado". Portanto, o espaço pode ser caracterizado pela instabilidade dos acontecimentos que nele ocorrem e pela forma como esses eventos são experenciados pelas pessoas que ali circulam.

As projeções nas paisagens urbanas rompem com a estabilidade do lugar, oferecendo novos sentidos para quem visualiza as imagens nos grandes edifícios, atualizando as possibilidades de viver e praticar a cidade. Tratam-se de eventos potentes e de alto impacto nas formas de ver a paisagem cotidiana, cujos registros são reverberados nas redes sociais.

As imagens projetadas nos edifícios têm caráter ativista e surgem como contravisualidades criativas que reinventam as estratégias de resistência em tempos de isolamento social. Cumprem a função de desestabilizar as mentiras e distorções que são difundidas pelo Estado, levando informações seguras à população. Mas, não se restringem somente ao aspecto político, disseminam, também, solidariedade, empatia, afeto e mensagens de esperança, por conseguinte, oferecem uma nova ênfase para pensar posicionalidades em um sentido amplo.

As práticas artísticas colaborativas normalmente entendem suas atividades como ferramentas de produção de conhecimento coletivo e funcionam como propagadoras de experiências. Podem gerar reflexões críticas importantes sobre as realidades locais, a depender dos sentidos e dos afetos que são experenciados e das identificações que podem ocorrer. É importante considerar que as experiências e as formas como aprendemos a ver estão atravessadas pelos dispositivos de normatização e de vigilância, portanto, a percepção sobre o que se vê não surge como um ato espontâneo, mas como consequência de certo campo de inteligibilidade cognitiva e possui estreita relação com os posicionamentos e as relações que são estabelecidas nas estruturas socioculturais e econômicas.

As contravisualidades que passamos a ver projetadas em grande formato nos edifícios das capitais brasileiras constroem outras narrativas, confrontam os discursos oficiais e amplificam as vozes dos sujeitos que buscam justiça social e representatividade. Ao confrontar notícias falsas, distorções e mentiras, os coletivos apresentam alternativas para ver o mundo com olhos menos inocentes e mais questionadores sobre os discursos que 
são difundidos no âmbito do poder hegemônico. Afinal, as contravisualidades tratam de "reivindicar o direito de olhar" (MIRZOEFF, 2011, p. 6), para que possamos inventar novos futuros, conforme nossas "verdades" subjetivas.

\section{Referências}

ARDĖVOL, E.; MUNTAÑOLA, N. Representación y cultura audiovisual en la sociedad contemporánea. Barcelona, Espanha: Editorial UOC, 2004. CERTEAU, Michel de. A invenção do cotidiano. 1. Artes de fazer. Petrópolis, RJ: Editora Vozes, 2019.

FOUCAULT, Michael. Segurança, Território, População: curso dado no Collège de France (1977-1978). São Paulo: Martins Fontes, 2008. HAN, Byung-Chul. Psicopolítica: o neoliberalismo e as novas técnicas de poder. (Trad. Mauricio Liesen). Belo Horizonte: Âyiné, 2018. MBEMBE, Achille. Necropolítica. In: Arte e Ensaios, 2(32), 2016, pp. 123-151. Recuperado de <https://revistas.ufrj.br/index.php/ae/article/ view/8993>. Em 25.03.20

MIRZOEFF, Nicholas. Cómo ver el mundo: Una nueva introducción a la cultura visual. Barcelona: Paidós, 2016.

MIRZOEFF. The Right to Look. In: Critical Inquiry, vol. 37, n. 3, 2011, pp. 473-496.

MITCHELL, W. J. T. O que as imagens realmente querem? In ALLOA (org.). Pensar a Imagem. Belo Horizonte: Autêntica Editora, 2015, pp. 165-190.

MITCHELL, W.J.T. Showing Seeing: A Critique of Visual Culture. Journal of Visual Culture, vol 1(2), 2002, pp. 65-181.

RAGO, Margareth; PELEGRINI, Maurício (orgs.). Neoliberalismo, Feminismo e Contracondutas. Perspectivas Foucaultianas. São Paulo: Intermeios, 2019.

ROLNIK, Suely. Esferas da Insurreição: notas para uma vida não cafetinada. São Paulo: Edições N-1, 2018, p. 138. 